\title{
SCIENTIFIC REPORTS

\section{Genotypic variations in leaf and whole-plant water use efficiencies are closely related in bread wheat genotypes under well-watered and water-limited conditions during grain filling}

Alejandro del Pozo $\mathbb{D}^{1 *}$, Ana María Méndez-Espinoza $\mathbb{1}^{1}$, Sebastián Romero-Bravo ${ }^{1,2}$, Miguel Garriga ${ }^{1}$, Félix Estrada ${ }^{1}$, Marta Alcaíno ${ }^{1}$, Anyela V. Camargo-Rodriguez ${ }^{3,4}$, Fiona M. K. Corke ${ }^{3}$, John H. Doonan ${ }^{3}$ \& Gustavo A. Lobos $\mathbb{1}^{1}$

Wheat plants growing under Mediterranean rain-fed conditions are exposed to water deficit, particularly during the grain filling period, and this can lead to a strong reduction in grain yield (GY). This study examines the effects of water deficit after during the grain filling period on photosynthetic and water-use efficiencies at the leaf and whole-plant level for 14 bread wheat genotypes grown in pots under glasshouse conditions. Two glasshouse experiments were conducted, one in a conventional glasshouse at the Universidad de Talca, Chile (Experiment 1), and another at the National Plant Phenomics Centre (NPPC), Aberystwyth, UK (Experiment 2), in 2015. Plants were grown under wellwatered (WW) and water-limited (WL) conditions during grain filling. The reductions in leaf water potential $(\Psi)$, net $\mathrm{CO}_{2}$ assimilation $(\mathrm{An})$ and stomatal conductance (gs) due to water deficit were 79,35 and $55 \%$, respectively, during grain filling but no significant differences were found among genotypes. However, chlorophyll fluorescence parameters (as determined on dark-adapted and illuminated leaves) and chlorophyll content (Chl) were significantly different among genotypes, but not between water conditions. Under both water conditions, An presented a positive and linear relationship with the effective photochemical quantum yield of Photosystem II ( $Y(I I))$ and the maximum rate of electron transport (ETRmax), and negative with the quantum yield of non-photochemical energy conversion in Photosystem II (Y(NPQ)). The relationship between $\mathrm{An}$ and $\mathrm{Chl}$ was positive and linear for both water conditions, but under WL conditions An tended to be lower at any Chl value. Both, instantaneous (An/E) and intrinsic (An/gs) water-use efficiencies at the leaf level exhibited a positive and linear relationship with plant water-use efficiency (WUEp = plant dry weight/water use). Carbon discrimination $\left(\Delta^{13} C\right.$ ) in kernels presented a negative relationship with WUEp, at both WW and WL conditions, and a positive relationship with GY. Our results indicate that during grain filling wheat plants face limitations to the assimilation process due to natural senesce and water stress. The reduction in An and gs after anthesis in both water conditions was mainly due a decline in the chlorophyll content (non-stomatal limitation), whereas the observed differences between water conditions were mainly due to a stomatal limitation.

${ }^{1}$ Centro de Mejoramiento Genético y Fenómica Vegetal, Facultad de Ciencias Agrarias, Universidad de Talca, Talca, Chile. ${ }^{2}$ Facultad de Ciencias Agrarias y Forestales, Universidad Católica del Maule, Curicó, Chile. ${ }^{3}$ National Plant

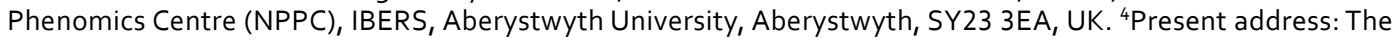
John Bingham Laboratory, National Institute of Agricultural Botany (NIAB), Cambridge, United Kingdom. *email: adelpozo@utalca.cl 
In Mediterranean climatic regions, annual average temperatures have increased and precipitation decreased during the last century ${ }^{1-3}$, and this phenomenon has also affected Chile ${ }^{4}$. In addition, precipitation in Chile is strongly concentrated in winter and also manifests large inter-annual variability. Thus, wheat plants growing under rainfed conditions are exposed to a progressive water deficit starting from heading, leading to a 'terminal drought stress', which reduces grain yield (GY). Therefore, enhancing crop resilience is a priority for Mediterranean environments and may also provide a better understanding of the physiological mechanisms underlying water stress tolerance in wheat.

Under drought stress, net $\mathrm{CO}_{2}$ assimilation (An), stomatal conductance (gs) and transpiration (E) all decrease during grain filling, changing the instantaneous water-use efficiency $(\mathrm{An} / \mathrm{E})$ and intrinsic water-use efficiency $(\mathrm{An} / \mathrm{gs})^{5-7}$. At the plant level, water use efficiency $(\mathrm{WUEp}=\mathrm{DW} / \mathrm{WU})$ corresponds to the coefficient between plant dry weight (DW) and the water-use (WU) by means of plant transpiration. According to Passioura $2006^{8}$, $\mathrm{GY}=\mathrm{WU} \times \mathrm{WUEp} \times \mathrm{HI}$, where $\mathrm{HI}$ is the harvest index $(\mathrm{GY} / \mathrm{DW})$, suggesting that under water stress conditions, the reduction in GY is a consequence of or at least correlated with lower WU and/or WUEp. If so, then the selection of genotypes with higher WU and/or WUEp should ameliorate the negative impact of water stress on GY. In a semi-controlled experiment, Guan et al. ${ }^{7}$ found a strong reduction in the WU and WUEp of wheat genotypes growing under water stress conditions, and significant genotypic differences for WU but not for WUEp. The above suggest a close relationship between the water use efficiency at leaf and plant level of wheat genotypes grown under different water conditions.

Terminal drought stress can also affect the properties and efficiency of the photosynthetic apparatus, particularly Photosystem II (PSII). Indeed, this is one of the first physiological processes affected, often prior to any other obvious stress symptoms ${ }^{9}$. Pulse amplitude modulated (PAM) fluorometry is a useful technique for identifying the amount of energy that is not used in photosynthesis but is re-emitted as fluorescence or dissipated as heat in the reaction centres, especially in $\mathrm{PSII}^{10,11}$. In particular, parameters from rapid light-response curves, which are quicker to obtain than the light response curves determined by infrared gas analysers, reveal key information about the rate of electrons travelling from PSII to PSI, and provide the photosynthetic photon flux density (PPFD) saturating the photosystems, and the efficiency with which electrons are used for photosynthesis ${ }^{12,13}$. There is little information about the relationship between An and parameters of chlorophyll fluorescence in wheat plants during grain filling under terminal drought stress.

Carbon isotope discrimination $\left(\Delta^{13} \mathrm{C}\right)$ in kernels represents another criterion for selecting high water-use efficiency genotypes ${ }^{14}$ and also provides an indirect determination of the effective water used by the crop ${ }^{15,16}$. Indeed, negative relationships between $\Delta^{13} \mathrm{C}$ and $\mathrm{An} / \mathrm{gs}$ have been reported in wheat and other $\mathrm{C} 3 \mathrm{crops}^{17-19}$.

The aims of this study were a) to evaluate the performance of the leaf photosynthetic apparatus; and b) to evaluate the relationships between water-use efficiencies at the leaf and whole-plant level, and the $\Delta^{13} \mathrm{C}$ in kernels in 14 wheat genotypes with different tolerance in terms of yield performance under terminal drought stress, in two contrasting water regimes during grain filling under glasshouse conditions. In a previous study we evaluated a large collection of 384 advanced wheat lines grown under water-limited and well-watered conditions ${ }^{20}$. We found large genotypic variability in grain yield under water-limited conditions, which was positively correlated with flag leaf chlorophyll content at anthesis and carbon discrimination in kernels, suggesting that cultivars that maintained higher levels of photosynthesis and conductance during grain growth were more productive. Also, the yield decrease under water-limited conditions during grain growth is related to various physiological changes including WU and water-use efficiency at the leaf and whole-plant level.

This characterisation should improve our understanding of genotype-dependent variation in water-use efficiency and its relationships with leaf water potential, leaf gas exchange, chlorophyll fluorescence and carbon isotope composition measurements (reverse phenomics), thus generating relevant information to be used for genotype selection (forward phenomics) under field conditions.

\section{Results}

Soil water content, leaf water potential and gas exchange. In experiment 1 , the soil water content was maintained at an average of 0.168 and $0.06 \mathrm{~m}^{3} \mathrm{~m}^{-3}$ for well-watered (WW) and water-limited (WL) conditions, respectively, from fully expanded flag leaves (8 September) until maturity (Supplementary Fig. 1). Under WL conditions, leaf water potential $(\Psi)$, An, gs and $\mathrm{E}$ at anthesis (Z65) were reduced by $32,18,38$ and $30 \%$, respectively, whereas at the hard dough grain stage (Z87) these were 79, 35, 55 and 50\%, respectively. However, no significant differences were found among genotypes (Table 1). The instantaneous and intrinsic WUE significantly increased under WL, with the interaction between genotype $\times$ water condition $(\mathrm{GxW})$ being highly significant (Table 1). All these traits exhibited a strong and significant reduction during grain filling, and in the case of $\Psi$ and internal $\mathrm{CO}_{2}$ concentration $(\mathrm{Ci})$, the water condition $\times$ phenology $(\mathrm{WxP})$ interaction was significant (Table 1$)$.

In experiment 2, the WL condition led to a strong reductions in An, gs and $\mathrm{E}$ at heading of 26, 44 and $40 \%$, respectively, but no significant differences were detected among the six genotypes (Table 2). The instantaneous and intrinsic WUE increased under WL conditions by 23 and 33\%, respectively. The GxW interaction was not significant for any of these traits (Table 2).

Chlorophyll fluorescence and content. The minimum (Fo) and maximum (Fm) fluorescence in the dark-adapted state, and the maximum photochemical quantum yield of PSII (Fv/Fm) were significantly different among the 14 genotypes (experiment 1), but between water conditions and the GxW interaction there were only significant differences for Fo; the genotype $\times$ phenology interaction was significant for the three parameters (Table 1). For the chlorophyll parameters determined under illuminated conditions, genotypic differences were detected for the minimum ( $\sim$ Fo') and maximum (Fm') chlorophyll fluorescence yield, effective photochemical quantum yield of PSII [Y(II)] and quantum yield of non-photochemical energy conversion in PSII due to down-regulation of the light-harvesting function [Y(NPQ)], but between the water conditions there were only 


\begin{tabular}{|c|c|c|c|c|c|c|c|c|c|c|}
\hline \multirow[b]{2}{*}{ Trait $^{\mathrm{a}}$} & \multicolumn{3}{|l|}{ WW } & \multicolumn{3}{|l|}{ WL } & \multicolumn{4}{|c|}{ ANOVA } \\
\hline & $\mathbf{A}$ & SD & HD & A & SD & HD & G & W & $\mathbf{P}$ & Interactions \\
\hline$\Psi(\mathrm{Mpa})$ & -0.55 & -0.58 & -1.01 & -0.73 & -0.93 & -1.82 & n.s. & $* * *$ & $* * *$ & WxP \\
\hline $\mathrm{An}\left(\mu \mathrm{mol} \mathrm{CO}{ }_{2} \mathrm{~m}^{-2} \mathrm{~s}^{-1}\right)$ & 21.1 & 14.7 & 7.6 & 17.2 & 12.0 & 4.9 & n.s. & $* * *$ & **** & n.s. \\
\hline $\mathrm{gs}\left(\mathrm{mmol} \mathrm{H}_{2} 0 \mathrm{~m}^{-2} \mathrm{~s}^{-1}\right)$ & 527.7 & 430.5 & 327.3 & 327.2 & 245.3 & 146.9 & n.s. & $* * *$ & $* * *$ & n.s. \\
\hline $\mathrm{E}\left(\mathrm{mmol} \mathrm{H} \mathrm{H}_{2} 0 \mathrm{~m}^{-2} \mathrm{~s}^{-1}\right)$ & 6.4 & 5.7 & 4.0 & 4.5 & 3.8 & 2.0 & $*$ & $* * *$ & **** & n.s. \\
\hline $\mathrm{Ci}\left(\mathrm{mmol} \mathrm{CO}_{2} \mathrm{~mol}^{-1}\right)$ & 271.7 & 287.4 & 320.5 & 252.2 & 267.1 & 311.3 & $* * *$ & $* * *$ & **** & GxW, WxP \\
\hline $\mathrm{An} / \mathrm{E}\left(\mu \mathrm{mol} \mathrm{CO} \mathrm{mmol} \mathrm{H}_{2} 0^{-1}\right)$ & 3.4 & 2.7 & 1.9 & 3.9 & 3.3 & 2.3 & $* * *$ & $* * *$ & $* * *$ & GxW, GxP \\
\hline $\mathrm{An} / \mathrm{gs}\left(\mu \mathrm{mol} \mathrm{CO} \mathrm{mol} \mathrm{H}_{2} 0^{-1}\right)$ & 43.0 & 38.9 & 24.2 & 58.0 & 53.8 & 33.9 & $* * *$ & $* * *$ & $* * *$ & GxW \\
\hline $\mathrm{F}_{0}(\mathrm{mv})$ & 1.55 & 1.72 & 1.74 & 1.54 & 1.69 & 1.64 & $* * *$ & **** & $* * *$ & GxP, WxP \\
\hline Fm (mv) & 6.89 & 6.90 & 6.47 & 6.90 & 6.90 & 6.36 & $* * *$ & n.s & $* * *$ & GxP \\
\hline $\mathrm{Fv} / \mathrm{Fm}$ & 0.80 & 0.76 & 0.72 & 0.80 & 0.76 & 0.75 & $* * *$ & n.s. & *** & GxP \\
\hline$\sim \mathrm{F}_{0}{ }^{\prime}(\mathrm{mv})$ & 1.39 & 1.46 & 1.30 & 1.37 & 1.45 & 1.23 & $* * *$ & $* *$ & $* * *$ & GxP \\
\hline Fm' (mv) & 3.35 & 3.58 & 2.64 & 3.33 & 3.60 & 2.54 & $* * *$ & n.s. & $* * *$ & GxP \\
\hline Alpha (e $\mathrm{e}^{-/}$photons) & 0.37 & 0.37 & 0.41 & 0.36 & 0.38 & 0.40 & n.s. & n.s. & $* * *$ & n.s. \\
\hline IK $\left(\mu \mathrm{mol}\right.$ photons $\left.\mathrm{m}^{-2} \mathrm{~s}^{-1}\right)$ & 286.7 & 195.9 & 137.8 & 296.5 & 208.8 & 150.4 & n.s. & n.s. & $* * *$ & n.s. \\
\hline $\operatorname{ETRmax}\left(\mu \mathrm{mol} \mathrm{e}^{-} \mathrm{m}^{-2} \mathrm{~s}^{-1}\right)$ & 99.6 & 74.8 & 55.9 & 102.7 & 75.8 & 59.6 & n.s. & n.s. & *** & n.s. \\
\hline $\mathrm{Y}(\mathrm{II})$ & 0.16 & 0.13 & 0.10 & 0.16 & 0.13 & 0.09 & $*$ & n.s. & $* * *$ & n.s. \\
\hline $\mathrm{Y}(\mathrm{NPQ})$ & 0.43 & 0.42 & 0.55 & 0.44 & 0.42 & 0.54 & $* * *$ & n.s. & $* * *$ & n.s. \\
\hline $\mathrm{Y}(\mathrm{NO})$ & 0.41 & 0.46 & 0.38 & 0.41 & 0.46 & 0.37 & n.s. & n.s. & *** & GxP \\
\hline Chl (Dualex units) & 46.69 & 42.48 & 12.86 & 46.81 & 44.12 & 13.12 & $* * *$ & n.s & $* * *$ & GxW, GxP \\
\hline
\end{tabular}

Table 1. Mean values $(\mathrm{N}=56)$ of leaf water potential, leaf gas exchange, chlorophyll fluorescence parameters and chlorophyll content determined at anthesis (A) and grain filling (soft dough-SD and hard dough-HD grain), of 14 genotypes growing in a glasshouse under well-watered (WW) and water-limited (WL) conditions (Experiment 1). G - genotype; $\mathrm{W}$ - water regime; $\mathrm{P}$ - phenology. ${ }^{\mathrm{a}} \mathrm{\Psi}$ : leaf water potential; An: leaf net $\mathrm{CO}_{2}$ assimilation; gs: stomatal conductance; $\mathrm{E}$ : transpiration rate; Ci: internal $\mathrm{CO}_{2}$ concentration; An/E: instantaneous water use efficiency; An/gs: intrinsic water use efficiency; $\mathrm{F}_{0}$ and Fm: minimum and maximum fluorescence in the dark-adapted state, respectively; Fv/Fm: maximum photochemical quantum yield of PSII; $\sim \mathrm{F}_{0}$ ' and Fm': respectively the calculated minimum and maximum chlorophyll fluorescence yield in PSII reaction centres in the open state; Alpha: initial slope of the light curve, related to maximum yield of photosynthesis; IK: PAR value of the point of intersection between the horizontal line ETRmax and the extrapolated initial slope; ETRmax: maximum rate of electron transport; $\mathrm{Y}(\mathrm{II})=(\mathrm{Fm}$ '-F)/Fm'): effective photochemical quantum yield of photosystem II; Y(NPQ): quantum yield of non-photochemical energy conversion in PS II due to down-regulation of the light-harvesting function; $\mathrm{Y}(\mathrm{NO})$ : quantum yield of nonphotochemical energy conversion in PS II other than that caused by down-regulation of the light-harvesting function; Chl: chlorophyll content. Significance levels: * $(\mathrm{P}<0.05), * *(\mathrm{P}<0.01), * * *(\mathrm{P}<0.001)$, n.s. (differences not significant; $\mathrm{P}>0.05$ ).

\begin{tabular}{|c|c|c|c|c|c|}
\hline \multirow[b]{2}{*}{ Trait $^{\mathrm{a}}$} & \multicolumn{2}{|c|}{ Water condition } & \multicolumn{3}{|c|}{ ANOVA } \\
\hline & WW & WL & G & W & GxW \\
\hline $\mathrm{An}\left(\mu \mathrm{mol} \mathrm{CO} \mathrm{C}^{-2} \mathrm{~s}^{-1}\right)$ & 14.60 & 10.83 & n.s. & $* *$ & n.s. \\
\hline gs $\left(\mathrm{mmol} \mathrm{H}_{2} 0 \mathrm{~m}^{-2} \mathrm{~s}^{-1}\right)$ & 172.01 & 96.05 & n.s. & $* * *$ & n.s. \\
\hline $\mathrm{E}\left(\mathrm{mmol} \mathrm{H} \mathrm{O} \mathrm{m}^{-2} \mathrm{~s}^{-1}\right)$ & 1.88 & 1.13 & n.s. & $* * *$ & n.s. \\
\hline $\mathrm{Ci}\left(\mathrm{mmol} \mathrm{CO}_{2} \mathrm{~mol}^{-1}\right)$ & 246.6 & 203.69 & n.s. & $* * *$ & n.s. \\
\hline $\mathrm{An} / \mathrm{E}\left(\mu \mathrm{mol} \mathrm{CO} \mathrm{mmol} \mathrm{H}_{2} 0^{-1}\right)$ & 7.93 & 9.77 & n.s. & $* * *$ & n.s. \\
\hline $\mathrm{An} / \mathrm{gs}\left(\mu \mathrm{mol} \mathrm{CO} \mathrm{mol} \mathrm{H}_{2} 0^{-1}\right)$ & 89.06 & 118.1 & n.s. & *** & n.s. \\
\hline $\operatorname{ETR}\left(\mu \mathrm{mol} \mathrm{e} \mathrm{e}^{-2} \mathrm{~s}^{-1}\right)$ & 96.69 & 88.49 & $*$ & n.s. & n.s. \\
\hline $\mathrm{Y}(\mathrm{II})$ & 0.15 & 0.14 & $*$ & n.s. & n.s. \\
\hline Chl (SPAD units) & 45.75 & 46.7 & $* * *$ & n.s. & n.s. \\
\hline
\end{tabular}

Table 2. Mean values $(n=30)$ of leaf gas exchange, chlorophyll fluorescence parameters and chlorophyll content determined at heading in six genotypes growing in a LemnaTec glasshouse under well-watered (WW) and water-limited (WL) conditions (Experiment 2). G - genotype; $\mathrm{W}$ - water regime. ${ }^{\mathrm{a}}$ Abbreviations are as in Table 2. Significance levels: $*(\mathrm{P}<0.05), * *(\mathrm{P}<0.01)$, $* * *(\mathrm{P}<0.001)$, n.s. (differences not significant; $\mathrm{P}>0.05)$.

significant differences for $\sim$ Fo' (Table 1 ). The chlorophyll parameters changed significantly with the phenological stage and the $\mathrm{WxP}$ interaction was significant in the case of Fo, Fm, Fv/Fm, Fo', Fm' and the quantum yield of non-photochemical energy conversion in PSII other than that caused by down-regulation of the light-harvesting function $[\mathrm{Y}(\mathrm{NO})]$ (Table 1). In Experiment 2, significant genotypic differences were observed for the maximum 

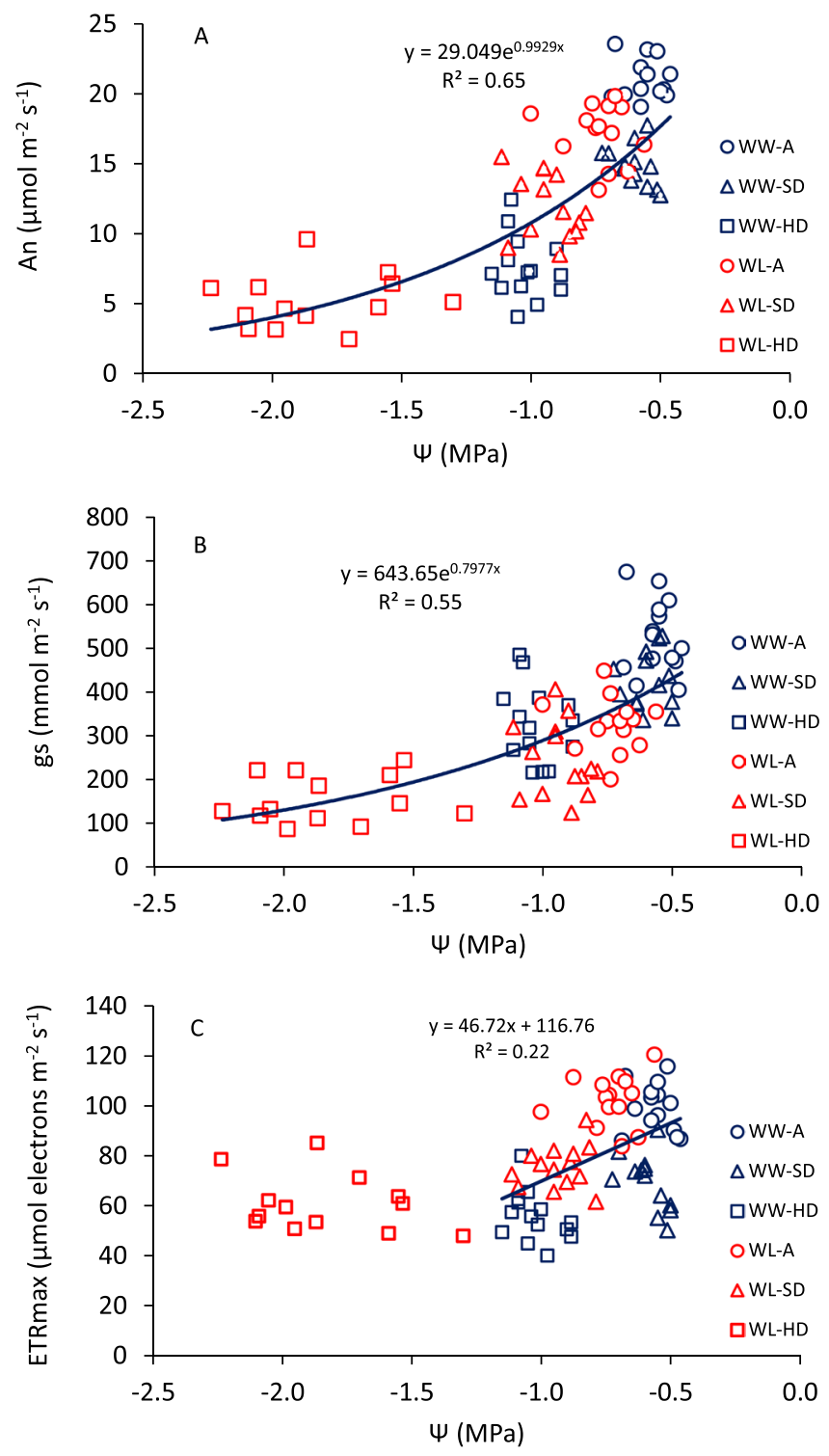

Figure 1. Relationships between leaf water potential and (A) net $\mathrm{CO}_{2}$ assimilation at light saturation (An), (B) stomatal conductance (gs) and (C) maximum rate of electron transport (ETRmax), determined at anthesis (A) and grain filling (soft dough-SD and hard dough-HD grain) of 14 genotypes of wheat grown under well-watered (WW) and water-limited (WL) conditions in a glasshouse. Values are the means of four replicate plants.

rate of electron transport (ETRmax) and Y(II), but there were no differences between water conditions or GxW interaction (Table 2).

The chlorophyll content was also significantly different among the 14 genotypes, as well as the genotype $\times$ water condition interaction (Table 1 ). Similarly in experiment 2 , the chlorophyll content was different among genotypes, but the GxW interaction was not significant (Table 2). No significant differences in Chl content were detected between water conditions in either experiment.

Relationships between leaf water potential, leaf gas exchange and chlorophyll fluorescence. Both An and gs decreased exponentially as the $\Psi$ declined from -0.5 to $-2.2 \mathrm{MPa}$, with no apparent differences in the response between water conditions. At $\Psi<-1.2 \mathrm{MPa}$, the leaves were under severe water stress, with An and gs reaching $5 \mu \mathrm{mol} \mathrm{m} \mathrm{m}^{-2} \mathrm{~s}^{-1}$ and $100 \mathrm{mmol} \mathrm{m}^{-2} \mathrm{~s}^{-1}$, respectively (Fig. 1A,B). In the case of ETRmax, the reduction occurred up to $\Psi=-1.2 \mathrm{MPa}$ and below that, ETRmax was on average $60 \mu \mathrm{mol} \mathrm{e}^{-} \mathrm{m}^{-2} \mathrm{~s}^{-1}$ (Fig. 1C).

Positive and curvilinear relationships were found between gs and An, ETRmax, Y(II) and the chlorophyll index (Chl), under WW and WL conditions (Fig. 2). In general, plants growing under WL exhibited higher levels of An, ETRmax, Y(II) and Chl compared to WW conditions, at any value of gs.

Under both water conditions, An presented a positive and linear relationship with Y(II) and ETRmax, and a negative relationship with Y(NPQ) (Fig. 3A-C); under WL, slopes and intercepts of the linear relationships were 

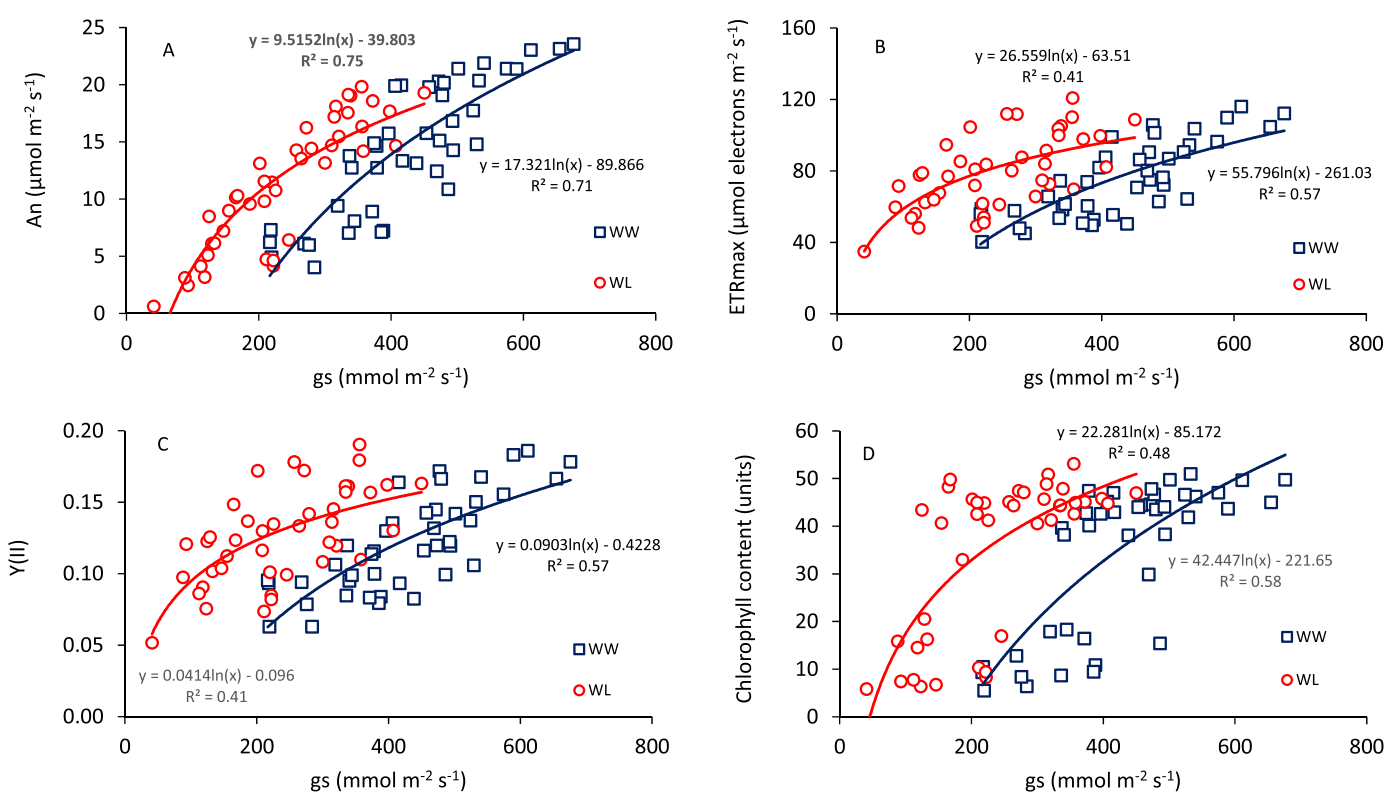

Figure 2. Relationship between stomatal conductance (gs) and (A) net $\mathrm{CO}_{2}$ assimilation at light saturation (An), (B) maximum electron transport (ETRmax), (C) effective photochemical quantum yield of photosystem II, and (D) the chlorophyll index (Dualex), determined at anthesis and grain filling in 14 genotypes of wheat grown in a glasshouse under well-watered (WW) and water-limited (WL) conditions. Each data point is the mean of four replicates.
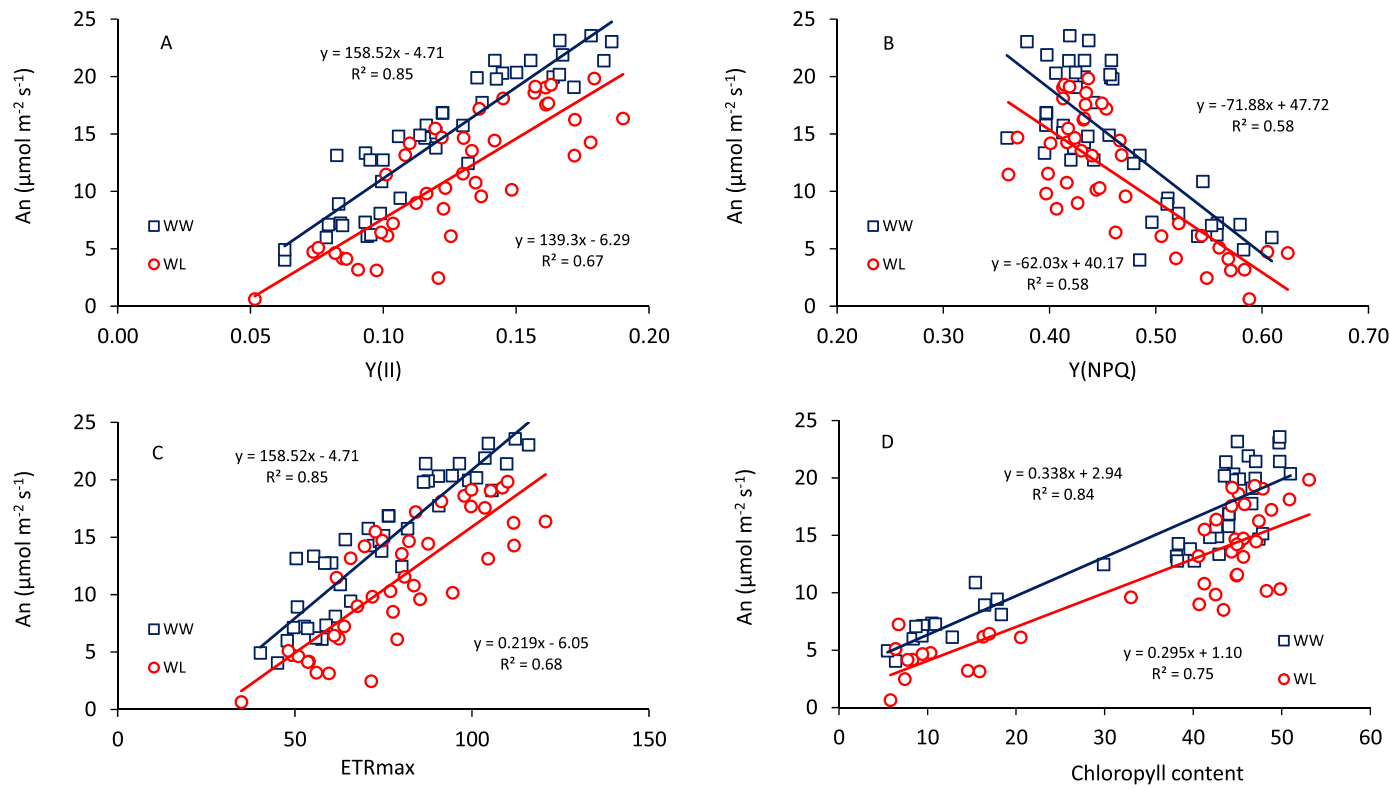

Figure 3. Relationship between leaf photosynthesis at light saturation (An) and (A) effective photochemical quantum yield of photosystem II, (B) quantum yield of non-photochemical energy conversion in PS II (Y(NPQ), (C) maximum electron transport (ETRmax) and (D) the chlorophyll index (Dualex), determined at anthesis and grain filling in 14 genotypes of wheat grown in a glasshouse under well-watered (WW) and waterlimited (WL) conditions. Each data point is the mean of four replicates.

slightly lower compared to WW conditions. The relationship between An and Chl was positive and linear for both water conditions, but under WL conditions An tended to be lower at any Chl value (Fig. 3D).

Green area, plant dry weight, dry matter partitioning, grain yield and yield components. The green area of the six genotypes (experiment 2) showed significant genotypic differences and large differences between water conditions (Fig. 4; Table 3). Under WL conditions, the green area declined soon after the water treatment started at 31 days after sowing when most genotypes presented fully expanded flag leaves (Z41). At 96 

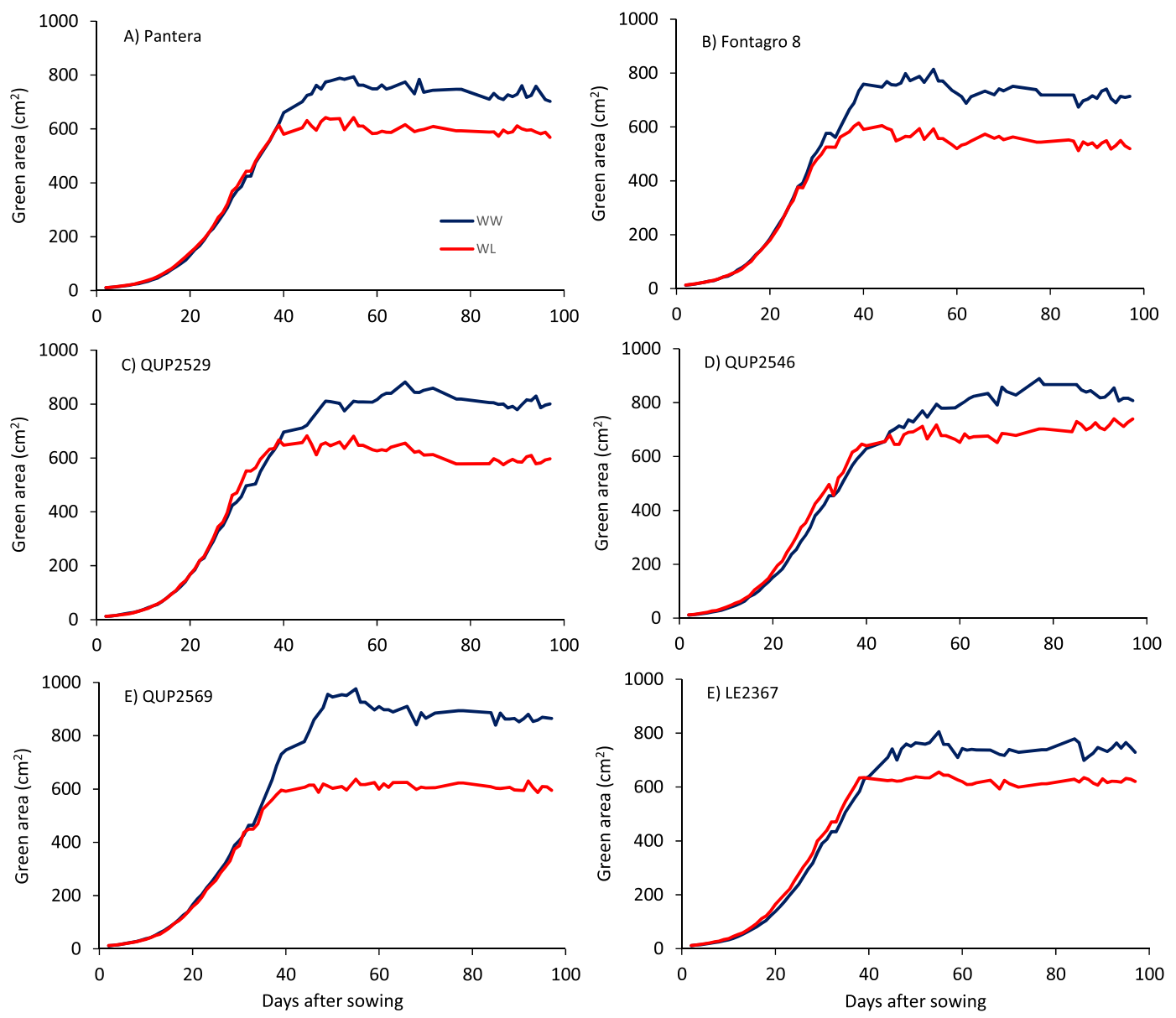

Figure 4. Average values $(n=5)$ of green area calculated for six genotypes of spring wheat grown in a LemnaTec glasshouse under well-watered (WW) and water-limited (WL) conditions in 2015 (Experiment 2). The beginning of the two water regimes was 31 days after sowing when most of the genotypes presented fully expanded flag leaves (Z41).

\begin{tabular}{|l|l|l|l|l|l|}
\hline \multirow{2}{*}{ Trait } & \multicolumn{4}{|l|}{ Water condition } & \multicolumn{2}{l|}{ ANOVA } \\
\cline { 2 - 7 } & WW & WL & G & W & GxW \\
\hline Green area $\left(\mathrm{cm}^{-2}\right)$ & 797.2 & 608.6 & $* * *$ & $* * *$ & n.s. \\
\hline Plant dry weight $(\mathrm{g})$ & 51.5 & 33.3 & $*$ & $* * *$ & $*$ \\
\hline Spike weight $(\mathrm{g})$ & 29.5 & 18.8 & n.s. & $* * *$ & n.s. \\
\hline Plant water use $\left(\mathrm{L} \mathrm{plant}^{-1}\right)$ & 16.1 & 9.6 & $*$ & $* * *$ & n.s. \\
\hline Plant WUE $\left(\mathrm{g} \mathrm{L}^{-1}\right)$ & 3.2 & 3.5 & n.s & $* * *$ & $*$ \\
\hline
\end{tabular}

Table 3. Mean values of green area, plant dry weight, spike weight, plant water use (WU) and plant water-use efficiency (WUE) of six genotypes growing in a LemnaTec glasshouse under well-watered (WW) and waterlimited (WL) conditions (Experiment 2). G - genotype; $\mathrm{W}-$ water regime. Significance levels: $*(\mathrm{P}<0.05)$, $* *(\mathrm{P}<0.01), * * *(\mathrm{P}<0.001)$, n.s. (differences not significant; $\mathrm{P}>0.05)$.

days after sowing, the average reduction in green area as a consequence of water deficit was $23.7 \%$. The strongest reduction in green area under WL conditions was observed in genotype QUP2569 and the lowest in QUP2546.

DW, GY, number of spikes per plant (SP), number of kernels per spike (KS) and per plant (KP), the thousand kernel weight (TKW), the root:shoot ratio (R:S), and the harvest index (HI) in experiment 1 exhibited significant differences among genotypes (Table 4). The effect of water condition was also significant except for KS, HI and R:S (Table 4). The average HI was high (>0.50) but there was one genotype (QUP2546-2009) that exhibited the lowest HI (0.38) in both water conditions. Under WL conditions, DW, GY and KP were reduced by about $25 \%$, while TKW increased by $4 \%$. The GxW interaction was not significant $(\mathrm{P}>0.05)$ for any trait (Table 4$)$. GY for the 14 genotypes presented positive and significant $(\mathrm{P}<0.001 ; \mathrm{n}=56)$ correlations with $\mathrm{SP}(\mathrm{r}=0.64$ and 0.48 for WW and WL, respectively), $\mathrm{KP}(\mathrm{r}=0.71$ and 0.59$)$ and $\mathrm{HI}(\mathrm{r}=0.54$ and 0.72$)$. In experiment 2 , DW was significantly 


\begin{tabular}{|l|l|l|l|l|l|}
\hline \multirow{2}{*}{ Trait } & \multicolumn{4}{|l|}{ Water condition } & \multicolumn{2}{l|}{ ANOVA } \\
\cline { 2 - 6 } & WW & WL & G & W & GxW \\
\hline Plant dry weight (g) & 35.3 & 26.5 & $* * *$ & $* * *$ & n.s. \\
\hline Grain yield (GY; g plant ${ }^{-1}$ ) & 17.0 & 13.0 & $* * *$ & $* * *$ & n.s. \\
\hline Spikes per plant & 6.4 & 5.0 & $* * *$ & $* *$ & n.s. \\
\hline Kernel per spike & 51.7 & 49.6 & $* *$ & n.s. & n.s. \\
\hline Thousand kernel weight (g) & 51.8 & 53.8 & $* * *$ & $* * *$ & n.s. \\
\hline Kernel per plant & 330.5 & 248.4 & $* * *$ & $* * *$ & n.s. \\
\hline Harvest index & 0.52 & 0.53 & $* * *$ & n.s. & n.s. \\
\hline Root:shoot & 0.10 & 0.09 & $*$ & n.s. & n.s. \\
\hline Plant water use (WU; L plant $\left.{ }^{-1}\right)$ & 7.3 & 4.9 & $* *$ & $* * *$ & n.s. \\
\hline Plant WUE (g L $\left.{ }^{-1}\right)$ & 4.9 & 5.5 & $* * *$ & $* * *$ & n.s. \\
\hline GY/WU (g L ( $\left.^{-1}\right)$ & 2.4 & 2.7 & $* * *$ & $* * *$ & n.s. \\
\hline$\Delta^{13}$ C in kernel (\%) & 20.31 & 19.02 & $* *$ & $* * *$ & n.s. \\
\hline
\end{tabular}

Table 4. Mean values of plant dry weight, grain yield and its agronomic components, dry matter partitioning, apparent water use, plant water-use efficiency (WUE) and carbon isotope discrimination in kernels $\left(\Delta^{13} \mathrm{C}\right)$, of 14 genotypes growing in a glasshouse under well-watered (WW) and water-limited (WL) conditions (Experiment 1). G - genotype; $\mathrm{W}$ - water regime. Significance levels: $*(\mathrm{P}<0.05), * *(\mathrm{P}<0.01)$, *** $(\mathrm{P}<0.001)$, n.s. (differences not significant; $\mathrm{P}>0.05$ ).
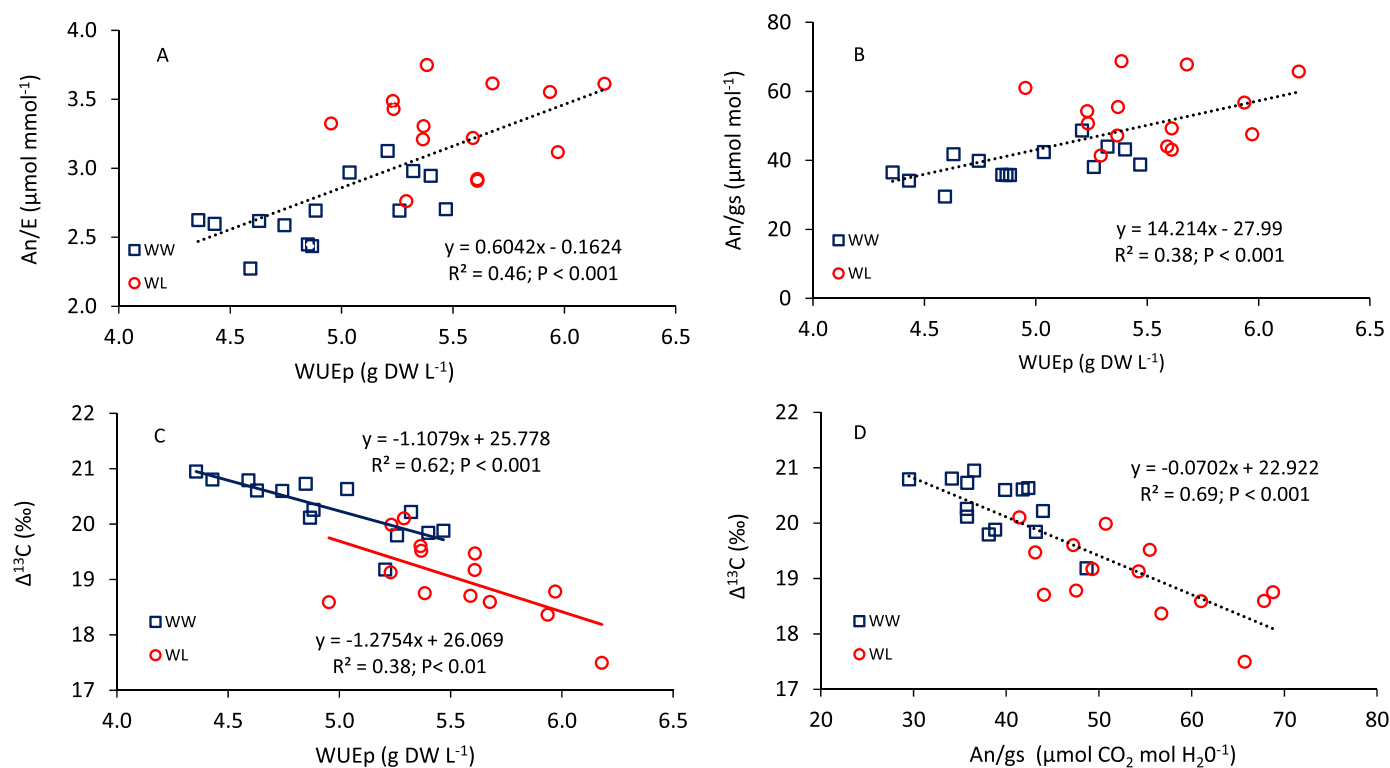

Figure 5. Relationships between plant water use efficiency (WUEp) and (A) instantaneous water use efficiency $(\mathrm{An} / \mathrm{E}),(\mathbf{B})$ intrinsic water use efficiency $(\mathrm{An} / \mathrm{gs})$ and $(\mathbf{C})$ carbon isotope discrimination in kernels $\left(\Delta^{13} \mathrm{C}, \%\right.$, and (D) between An/gs and $\Delta^{13} \mathrm{C}$, of 14 genotypes of wheat grown under well-watered (WW) and water-limited (WL) conditions in a glasshouse. Data for $\mathrm{An} / \mathrm{E}$ and $\mathrm{An} / \mathrm{gs}$ were measured at grain filling (soft dough grain) and values are the means of four replicate plants.

different $(\mathrm{P}<0.05)$ among genotypes, as was the $\mathrm{GxW}$ interaction (Table 3$)$. The WL condition reduced DW by $35 \%$ and the spike weight by $36 \%$ (Table 3 ).

Plant water-use, water-use efficiency and carbon isotope discrimination in grain. The WU per plant was reduced under WL conditions after the start of the water treatment (Supplementary Fig. 2). The total WU during the whole growing period was significantly different $(\mathrm{P}<0.01)$ among genotypes and between water conditions, but the GxW interaction was not significant in either experiment. Under WL conditions, the average plant WU decreased by 33 and 40\% in experiments 1 and 2, respectively (Tables 3 and 4).

WUEp under WL conditions increased by $12 \%$ and $9 \%$ in experiments 1 and 2, respectively (Tables 3 and 4). Differences among water conditions were significant $(\mathrm{P}<0.001)$ in both experiments, but the GxW interaction was only significant $(\mathrm{P}<0.05)$ in experiment 2 . The water productivity $(\mathrm{GY} / \mathrm{WU})$ under $\mathrm{WL}$ conditions was also increased by $13 \%$ in experiment 1 , and was significantly different $(\mathrm{P}<0.001)$ among genotypes (Table 4$). \Delta^{13} \mathrm{C}$ was also different among genotypes $(\mathrm{P}<0.01)$, and was significantly higher $(\mathrm{P}<0.001)$ under WW conditions (Table 4). WUEp determined under WW and WL conditions presented a positive and linear relationship with 


\begin{tabular}{|c|c|c|c|c|c|}
\hline \multirow[b]{2}{*}{ Genotype name } & \multirow[b]{2}{*}{ Pedigree } & \multirow{2}{*}{\begin{tabular}{|l|}
$\mathrm{GY}_{\mathrm{WS}}$ \\
$\left(\mathrm{Mg} \mathrm{ha}^{-1}\right)$
\end{tabular}} & \multirow{2}{*}{\begin{tabular}{|l|}
$\mathrm{GY}_{\mathrm{FI}}$ \\
$\left(\mathrm{Mg} \mathrm{ha}^{-1}\right)$ \\
\end{tabular}} & \multirow[b]{2}{*}{ YTI $^{*}$} & \multirow[b]{2}{*}{ Experiment } \\
\hline & & & & & \\
\hline QUP2418-2007 & ALTAR84/AE.SQUA (221)//SIREM/3/SRMA/TUI & 5.5 & 12.0 & 0.67 & 1 \\
\hline QUP2546-2009 & MILAN/PASTOR//DOMO & 5.4 & 10.2 & 0.56 & 1 and 2 \\
\hline FONTAGRO 8 & KA/NAC//SERI/RAYON & 5.0 & 10.2 & 0.52 & 1 and 2 \\
\hline LE 2367 & LE2265/LE2304 & 4.9 & 9.5 & 0.47 & 1 and 2 \\
\hline QUP2529-2009 & RL6043/4*NAC//QUP 1861_96 & 4.3 & 10.1 & 0.44 & 1 and 2 \\
\hline QUP2474-2007 & SITE//BUC/PVN/3/QUELEN & 4.0 & 10.8 & 0.44 & 1 \\
\hline PANTERA-INIA & TJB358.251/BUC//CIKO & 3.4 & 11.0 & 0.38 & 1 and 2 \\
\hline FONTAGRO 92 & PFAU/BOW//VEE\#9/3/WBLL1 & 4.1 & 9.0 & 0.37 & 1 \\
\hline QUP2405-2006 & QUP 1865_96/CAR3911//QUP 1865_96 & 3.8 & 9.4 & 0.36 & 1 \\
\hline QUP2616-2009 & PFAU/WEAVER*2//PAVON 7S3, + LR47 & 3.2 & 10.3 & 0.33 & 1 \\
\hline LE 2384 & BAG10/B. Sureño & 3.4 & 9.1 & 0.31 & 1 \\
\hline PANDORA-INIA & TJB358.251/BUC//CIKO & 2.8 & 9.3 & 0.26 & 1 \\
\hline QUP2569-2009 & MILAN/PASTOR//DOMO & 2.0 & 10.2 & 0.21 & 1 and 2 \\
\hline FONTAGRO 98 & $\begin{array}{l}\text { FILIN/IRENA/5/CNDO/R143//ENTE/MEXI_2/3/AEGILOPS } \\
\text { SQUARROSA(TAUS)/4/WEAVER/6/BERKUT }\end{array}$ & 1.6 & 9.2 & 0.15 & 1 \\
\hline
\end{tabular}

Table 5. Selected genotypes, grain yield (GY) and the yield tolerance index (YTI) determined at two Mediterranean sites, Cauquenes under water stress (WS) and Santa Rosa under full irrigation (FI) conditions, in 2012. Experiment 1 and 2 refers to the trial conducted in a conventional glasshouse at the Plant Breeding and Phenomic Center, Talca, Chile, and in a LemnaTec glasshouse at the National Plant Phenomics Centre (NPPC), Aberystwyth, UK, respectively. The genotypes were selected from a set of 384 genotypes (del Pozo et al. ${ }^{20}$. ${ }^{*} \mathrm{YTI}=\mathrm{Y}_{\mathrm{WS}} \mathrm{Y}_{\mathrm{FI}} / \bar{\Upsilon}_{\mathrm{FI}}^{2}$ where $\mathrm{Y}_{\mathrm{WS}}$ and $\mathrm{Y}_{\mathrm{FI}}$ are the genotype yield under water stress (Cauquenes) and full irrigation conditions (Santa Rosa), respectively, and $\bar{Y}_{\mathrm{FI}}$ is the mean yield of all genotypes under FI conditions; the higher the YTI value the better the performance of the genotype under rainfed conditions.

the instantaneous $(\mathrm{An} / \mathrm{E})$ and intrinsic (An/gs) water-use efficiencies evaluated at grain filling (Fig. 5A,B) or at anthesis (not shown), but had a negative relationship with $\Delta^{13} \mathrm{C}$ (Fig. $5 \mathrm{C}$ ). In addition, $\Delta^{13} \mathrm{C}$ showed a negative and linear relationship with An/gs (Fig. 5D) and a positive correlation with $\mathrm{GY}(\mathrm{r}=0.6 ; \mathrm{P}<0.001, \mathrm{n}=28)$.

\section{Discussion}

Agronomic traits. The 14 advanced wheat lines and cultivars evaluated in this work exhibited a high phenotypic variability for leaf and whole-plant traits. The genotypes have a very different genetic background except for cvs. Pantera-INIA and Pandora-INIA, which are very similar because Pantera-INIA is a Clearfield ${ }^{\circledR}$ cultivar with resistance to the herbicide imidazolinone following introduction of the Ser-Asn627 mutation into two acetolactate synthase (ALS) genes (imil and imi2), located in wheat on chromosomes 6B and 6D, respectively, into cv. Pandora-INIA, by a biotechnological procedure ${ }^{21}$. In experiment 1, the average DW, GY and HI of Pandora-INIA and Pantera-INIA were not significantly different $(\mathrm{P}<0.05)$, however, field experiments conducted in different environments showed consistently high GY in Pantera-INIA (http://www.semillasinia.cl/wp-content/uploads/2012/09/FolletoPanteraINIA.pdf ${ }^{20}$;), indicating that the two cultivars probably respond differently to agronomic management.

The strong correlation between HI and GY $(r=0.72 ; \mathrm{P}<0.001)$ under WL conditions suggests that the partitioning of the aboveground biomass to the grain is an important trait for selecting genotypes for high-yielding and drought-prone environments where water deficit occurs mainly during grain filling. Retrospective studies of old and modern cultivars in Mediterranean environments have shown that progress in breeding for yield after 1900 has been strongly associated with increases in $\mathrm{HI}$ in bread ${ }^{15,22}$ and durum wheat ${ }^{23}$.

Photosynthetic traits. The strong decline in An, gs and $\mathrm{E}$ from anthesis to the hard dough grain stage under both water conditions (Table 1) was associated with a decrease in $\Psi$ and Chl content during grain growth (Fig. 1). However, no genotypic differences in A and gs were detected among genotypes (Tables 1 and 2), probably because all the material was modern and possessed high yield potential under well-watered conditions (Table 5). Other studies comparing wheat cultivars (from different years of release) under well-watered conditions have reported an increase of gs in modern cultivars in close relationship with GY; for instance, in $\mathrm{Mexico}^{24}$, China ${ }^{25}$ and Chile ${ }^{22}$. A recent study conducted on 64 field-grown wheats in the UK demonstrated that photosynthetic traits (leaf gas exchange and chlorophyll a fluorescence) were positively correlated with GY and harvest inde ${ }^{26}$. During grain filling in the current work, both An and Chl decreased as a consequence of the process of leaf senescence, explaining the positive correlation between both traits (Fig. 3D). However, the Chl content of flag leaves was similar in both water conditions (Tables 1 and 2). In addition, the Chl content exhibited significant genotype $\times$ phenology and genotype $\times$ water condition interactions (Table 1), suggesting that some genotypes may present a more delayed senescence (stay-green). There is evidence that the stay-green phenotype or plants with delayed leaf senescence can improve their performance under drought conditions ${ }^{27,28}$. For example, durum wheat (Triticum turgidum ssp. durum) mutants growing under glasshouse conditions remained green for longer and had higher rates of leaf photosynthesis and larger seed weight ${ }^{29}$. Other studies conducted in field conditions reported a positive correlation between the stay-green trait and $\mathrm{GY}^{30,31}$. This capacity for maintaining photosynthetic rates under stress conditions is related to the capacity of stay-green genotypes to have low chlorophyll $\mathrm{a} / \mathrm{b}$ ratios and more chlorophyll $\mathrm{a}$ and $\mathrm{b}$ content than genotypes 
without this characteristic ${ }^{32}$. Therefore, this ideotype also shows high values of parameters associated with efficient conversion of photosynthetic energy, such as Y(II) or ETRmax ${ }^{33}$.

Chlorophyll fluorescence parameters determined in dark-adapted leaves (Fo, Fm and Fv/Fm) and light-adapted leaves ( Fo', Fm', Y(II) and Y(NPQ)) exhibited significant differences among genotypes (Tables 1 and 2). For example, Pantera-INIA presented 10\% higher values for Y(NPQ) and $9 \%$ lower for Y(NO) at anthesis and grain filling, under WL conditions, and this may explain the better performance of Pantera-INIA in rainfed conditions. A study of 144 genotypes of durum wheat, cultivated in three Mediterranean conditions, demonstrated that Fo and Fm had a strong genotypic effect and also exhibited high broad-sense heritabilities ${ }^{34}$. Also, the same authors reported that Fo, Fm and Fv/Fm were significantly correlated with GY.

Fv/Fm and Y(II) are widely used as indicators of the degree plant stress and as criteria for genotype selection, in drought or heat ambient ${ }^{35-37}$. Decreases in both parameters are associated with greater heat release in the antenna complex and the reduction in the amount of light energy used for photosynthesis increases photo-oxidative damage ${ }^{38,39}$. In this work Fm', Fv/Fm and Y(II) decreased during grain filling under WW and WL conditions, but no differences were detected between the two water conditions (Table 1), indicating that PSII was not damaged during the water stress, and the decline in An was mainly due to stomatal limitation ${ }^{40}$. In addition, changes in gs and An during grain filling were closely related to changes in ETRmax and Y(II) (Figs. 2 and 3). It has been suggested that a decrease in Rubisco activity in C3 plants typically occurs at lower gs $<100 \mathrm{mmol}$ $\mathrm{H}_{2} 0 \mathrm{~m}^{-2} \mathrm{~s}^{-1}$, whereas permanent biochemical limitations are observed at very low gs $\left(<50 \mathrm{mmol} \mathrm{H}_{2} 0 \mathrm{~m}^{-2} \mathrm{~s}^{-141}\right.$. Under water deficit conditions, it was observed that at gs $<\sim 100 \mathrm{mmol} \mathrm{H}_{2} 0 \mathrm{~m}^{-2} \mathrm{~s}^{-1}$, which occurred at the hard dough grain stage, there was a strong decline in An, ETRmax and Y(II) (Fig. 3), indicating non-stomatal limitations $^{41}$. Under WW conditions, the non-stomatal limitations started at higher gs compared with WL conditions, and this could have been a consequence of the leaf senescence process.

The decrease or loss of photosynthetic capacity in plants is an inherent process of senescence, which is more pronounced under water deficit. However, biochemical limitations appear mainly in late stages of grain filling or under severe water deficit ${ }^{42-44}$. As the flag leaf senesced (in either water condition), the chlorophyll content and the Fm' values declined (Table 1), which indicates that the PSII centres were partially closed (Quinone A reduced) and that the excess energy dissipated mainly via heat emission ${ }^{9}$. Thus, the performance of the photosynthetic process during grain growth was affected by stomatal and non-stomatal limitations ${ }^{40,45,46}$.

Leaf and whole-plant water-use efficiencies, and carbon discrimination. When water deficits start to build up, both leaf water potential and stomatal conductance decrease faster than carbon assimilation, leading to an increase in instantaneous and intrinsic water-use efficiency ${ }^{47}$. The relationship between gs and An in flag leaves evaluated at anthesis and grain filling (Fig. 2) indicated that An/gs was higher under WL conditions in all genotypes. It seems that an acclimation process occurred at the leaf level when wheat plants were exposed to terminal water stress, leading to a better use of the available water. The genotypic differences in An/gs and An/E, and also the significant GxW interaction found at anthesis and grain filling (Tables 1 and 2) suggests that genotypes have different sensitivity to the water deficit. In a comparison of six wheat genotypes Skider et al. ${ }^{6}$ also found a strong reduction in $\mathrm{An} / \mathrm{E}$ and $\mathrm{An} / \mathrm{gs}$ under water deficit conditions, and reported a significant GxW interaction.

The water deficit during grain filling (terminal drought) caused a strong and rapid reduction in the green area (Fig. 4), as well as the WU and DW (Tables 3 and 4). Because the terminal drought produced a stronger reduction in WU (33 and 40\% in experiments 1 and 2, respectively) compared to the observations for DW (25 and 35\%, respectively), there was an increase in WUEp under WL conditions. This was also observed in the water-use efficiency evaluated at the leaf level (An/E and An/gs). Indeed, the genotypic variability in WUEp under WW and WL conditions was closely related to the variability observed in An/E and An/gs (Fig. 5). Here, the scaling up from single leaf to the whole plant revealed significant correlations, but this is not always the case, particularly in field-grown plants ${ }^{48}$. Indeed, a positive and significant correlation $(r=0.66 ; \mathrm{P}=0.014, \mathrm{~N}=13)$ was observed between the GY of the genotypes in Mediterranean rainfed (water stress) conditions and the water productivity (GY/WU) determined under WL conditions in experiment 1, when the genotype with the lowest HI (QUP25462009) was excluded from the analysis.

The above observations raise the question of which types of genotypes should be selected for Mediterranean conditions. Selecting for higher WUEp has usually led to drought-tolerant genotypes with lower WU and biomass and, therefore, reduced grain yield. Perhaps our target should be genotypes with higher biomass and HI under water-limiting conditions, although this implies higher WU.

Carbon discrimination in kernels was negatively correlated to WUEp and An/gs (Fig. 5), as reported by other authors in wheat genotypes ${ }^{19,49}$, and positively correlated with GY. In fact, the $\Delta^{13} \mathrm{C}$ in kernels can be positive or negatively correlated with GY depending on soil water availability ${ }^{20,50-52}$. In Mediterranean conditions, negative relationships between GY and $\delta^{13} \mathrm{C}$ (or positive with $\Delta^{13} \mathrm{C}$ ) have been frequently reported in cereals $\mathrm{s}^{22,50,51,53}$ and this can be explained as the genotypes exhibiting the highest water use also tending to be the most productive $^{16,51,54}$. It also indicates that more productive genotypes are those maintaining stronger transpiration and thus increased water-use. Therefore, in wheat breeding programs oriented towards water-limiting conditions, efforts should focus on the identification of individuals with the capacity to generate greater biomass and HI, and with the associated higher WU and transpiration rates ${ }^{16}$.

\section{Conclusions}

The 14 chosen spring bread wheat genotypes had contrasting GY under WL conditions and exhibited high phenotypic variability for WU and WUEp as evaluated in LemnaTec and conventional glasshouses. The WL conditions during grain filling (terminal drought) led to an abrupt interruption of green area development, a reduction in DW, and an improvement in WUE at the leaf and plant levels. The reduction in GY under WL conditions was 
associated with lower numbers of spikes per plant and kernels per plant, but not the TKW, which was slightly higher under WL conditions. It is possible that the lower number of kernels per plant reduced the competition from assimilates.

In Mediterranean environments, wheat plants experience natural senesce and water stress during grain filling, which both induce limitations on the assimilation process. The reduction in An and gs after anthesis under both water conditions was mainly due a reduction in the chlorophyll content (non-stomatal limitation), whereas the observed differences between water conditions were mainly due to stomatal limitation. The chlorophyll fluorescence parameters determined in dark-adapted leaves (Fo, Fm and Fv/Fm) and light-adapted leaves ( Fo', Fm', $\mathrm{Y}(\mathrm{II})$ and $\mathrm{Y}(\mathrm{NPQ})$ ) did not exhibit significant differences between water conditions, except for Fo and $\sim$ Fo'. Indeed, the Chl content was similar in both water conditions, and this could explain the increase in WUE at the leaf level under water stress. The genotypic variabilities in $\mathrm{An} / \mathrm{E}$ and $\mathrm{An} / \mathrm{gs}$ were closely related to the variability observed in WUEp. Carbon discrimination $\left(\Delta^{13} \mathrm{C}\right)$ in kernels was negatively correlated with An/gs and positively correlated with GY.

\section{Materials and Methods}

Plant material, growing conditions and experimental design. Two experiments were conducted under glasshouse conditions. In Experiment 1, a set of 14 contrasting advanced spring bread wheat lines and cultivars with similar phenology were selected (according to their yield tolerance index (YTI) evaluated under field conditions (rain fed $v$ s. full irrigation) from a previous study of 384 genotype $^{20}$ (Table 5). Experiment 1 was performed at the Plant Breeding and Phenomic Center ( $35^{\circ} 24^{\prime} 19^{\prime \prime}$ S; $\left.71^{\circ} 37^{\prime} 59^{\prime \prime} \mathrm{W}\right)$, Universidad de Talca, Talca, Chile, from 3 July to 13 November 2015. The glasshouse had natural lighting and a heating system; mean temperatures in the glasshouse ranged from $9-21^{\circ} \mathrm{C}$, and the daily average for the growing period was $16^{\circ} \mathrm{C}$ (Supplementary Fig. 3). On 3 July 2015, ten seeds of each genotype were sown in $7.5 \mathrm{~L}$ pots of $26 \mathrm{~cm}$ in diameter and $21.1 \mathrm{~cm}$ height, filled with a 1:1:1 mixture of organic soil mixture (Anasac, Chile), perlite and river sand, representing a total weight per pot of $4.9 \mathrm{~kg}$. After the emergence of the second leaf, the seedlings were thinned to five per pot. The soil moisture content of all pots was kept at $75 \%$ field capacity (FC) of the substrate until the flag leaf was fully expanded (Zadoks stage Z41) ${ }^{55}$ in most genotypes (8 September). To obtain the maximum water holding capacity the pots were watered until saturation and after 24 hours of free drainage were weighed to determine the amount of water required to reach $100 \%$ of FC $(1,800 \mathrm{ml}$ of water per pot). Therefore, $75 \%$ and $30 \% \mathrm{FC}$ corresponded to $1,350 \mathrm{ml}$ and $540 \mathrm{ml}$ per pot, respectively. To maintain these two water conditions, each pot was weighed daily before and after each irrigation, and the water was replenished until the weights set in each treatment were reached. Additionally, soil water content $\left(\mathrm{m}^{3} \mathrm{~m}^{-3}\right)$ was monitored using automatic sensors (EC-5, Decagon Devices Inc., WA, USA) installed at $5 \mathrm{~cm}$ depth and connected to a datalogger (EM-50, Decagon Devices Inc., WA, USA); there were three sensors per water condition (Supplementary Fig. 1). Micro- and macro-nutrient fertilisation was applied using Hoagland nutrient solution, at the rate of $200 \mathrm{ml}$ per pot per week, from 15 July to 3 September 2015. The experimental design was completely randomised with two factors, genotype and water condition, and four replicates.

In Experiment 2, a subset of five contrasting advanced lines, four tolerant and one susceptible, and one cultivar (Table 5) were grown under LemnaTec glasshouse conditions at the National Plant Phenomics Centre (NPPC), Aberystwyth University, UK. Temperature conditions were kept between 18 and $20^{\circ} \mathrm{C}$. Natural lightning was supplemented with $600 \mathrm{~W}$ sodium lamps $\left(\sim 400 \mu \mathrm{mol} \mathrm{m}^{-2} \mathrm{~s}^{-1}\right)$ on cloudy days. On 07 May 2015 , two seeds per pot were sown in $1 \mathrm{~L}$ pots filled with Levington F2 compost. After germination the seedlings were thinned to one per pot. Plants were transferred to the glasshouse where each pot was placed into a cart on a conveyor system. Pots were weighed and watered automatically to $75 \%$ gravimetric water content daily. After the flag leaf was fully expanded (Z41; 10 June), a set of plants were kept at 75\% field capacity (WW) and another at 30\% FC (WL), giving a total of 60 plants. The experimental design was completely randomised with two factors, genotype and water condition, and five replicates.

Leaf water potential, gas exchange, chlorophyll fluorescence and content. In Experiment 1, all measurements at leaf level were taken from the middle part of flag leaves of three plants per pot, under clear sky conditions and between 12 and $16 \mathrm{~h}$. An average of three leaves was calculated for each replicate. Leaf water potential $(\Psi)$ was determined using a pressure chamber (PMS 600, PMS Instrument Co., OR, USA). In order to equilibrate the potential of the leaf with the stem, flag leaves were covered with adhesive plastic film and aluminium foil for $2 \mathrm{~h}$ before measurements. Leaf net $\mathrm{CO}_{2}$ assimilation (An), stomatal conductance (gs), internal $\mathrm{CO}_{2}$ concentration $(\mathrm{Ci})$ and transpiration rate $(\mathrm{E})$ were determined on flag leaves at three phenological stages $(\mathrm{P})$ : anthesis (Z65) and soft (Z83) and hard dough grain (Z87), Zadoks et al..$^{55}$, using a portable infra-red gas analyser (CIRAS 2, PP System, England). Measurements were performed using a cuvette of $1.7 \mathrm{~cm}^{2}$ of leaf area, at a flow rate of $250 \mathrm{ml} \mathrm{min}^{-1}$, reference $\mathrm{CO}_{2}$ of $380 \mu \mathrm{mol} \mathrm{mol}^{-1}$, leaf temperature of $25^{\circ} \mathrm{C}$ and photosynthetic photon flux density (PPFD) of $1,500 \mu \mathrm{mol} \mathrm{m}{ }^{-2} \mathrm{~s}^{-1}$. The instantaneous and intrinsic water-use efficiencies were calculated as An/E and An/gs, respectively.

PAM fluorescence was assessed with a portable fluorometer (PAM-2500, Walz, Germany) using the same leaves and phenological stages used to determine gas exchange. Minimum (Fo) and maximum (Fm) fluorescence in the dark-adapted state, and the maximum photochemical quantum yield of PSII (Fv/Fm) were assessed using leaf clips (DLC-8, Walz, Germany). Leaves were dark-acclimated for $20 \mathrm{~min}$ before measurements were taken. Next, each leaf clip was opened and, after at least $30 \mathrm{~min}$ of light acclimation, rapid light-response curves (RLCs) were determined using the amplitude modulated pulse mode; for each measurement the equipment provided 10 pulses every $6 \mathrm{~s}$, which increased light from $0 \mu \mathrm{mol} \mathrm{m} \mathrm{m}^{-2} \mathrm{~s}^{-1}$ to $2,000 \mu \mathrm{mol} \mathrm{m} \mathrm{m}^{-2} \mathrm{~s}^{-1}$. After each pulse, the equipment delivered a saturating light pulse $\left(10,000 \mu \mathrm{mol} \mathrm{m}^{-2} \mathrm{~s}^{-1}\right)$, which allows the calculation of the minimum $\left(\sim \mathrm{F}_{0}{ }^{\prime}\right)$ and maximum (Fm') chlorophyll fluorescence yield during the open state of PSII reaction centres. In the 
RLC, at 1,500 $\mu \mathrm{mol} \mathrm{m} \mathrm{m}^{-2} \mathrm{~s}^{-1}$, the following parameters were calculated: $\mathrm{Y}(\mathrm{II})$ : effective photochemical quantum yield of PSII [(Fm'-F)/Fm'], where F is the fluorescence shortly before a saturating pulse; (Y(NPQ): quantum yield of non-photochemical energy conversion in PSII due to down-regulation of the light-harvesting function $\left[\left(\mathrm{F} / \mathrm{Fm}{ }^{\prime}\right)-(\mathrm{F} / \mathrm{Fm})\right]$; and $\mathrm{Y}(\mathrm{NO})$ : quantum yield of non-photochemical energy conversion in PSII other than that caused by down-regulation of the light-harvesting function $[(\mathrm{F} / \mathrm{Fm})]$. After fitting the RLC, the following parameters were determined with the equations described by Eilers and Peeters $1988^{56}$ : Alpha: initial slope of the light curve, related to the maximum yield of photosynthesis; ETRmax: maximum rate of electron transport; and IK: PAR value at the intersection of alpha and ETRmax. Following gas exchange and modulated chlorophyll fluorescence assessments, the chlorophyll content was estimated using a portable non-destructive chlorophyll meter (Dualex Scientific, Force-A).

In Experiment 2, leaf gas exchange was determined at heading (Z59; Zadoks et al.$^{55}$ ) using a portable infrared gas analyser with a PAM-Fluorometer (WALZ GFS-3000FL). The cuvette had an area of $4 \mathrm{~cm}^{2}$ and measurement conditions were a $700 \mu \mathrm{mol} \mathrm{min}{ }^{-1}$ flow rate, $400 \mu \mathrm{mol} \mathrm{mol}^{-1}$ of reference $\mathrm{CO}_{2}, 24^{\circ} \mathrm{C}$ leaf temperature, $1,500 \mu \mathrm{mol}$ $\mathrm{m}^{-2} \mathrm{~s}^{-1}$ of PPFD and 60-65\% relative humidity. Measurements were taken from five flag leaves per genotype and water condition. Chlorophyll content was determined using a portable non-destructive chlorophyll meter (SPAD 502, Minolta).

Image system and analysis for green area determination (Experiment 2). Plants were transported by conveyer through an imaging cabinet hosting a RGB camera, with images taken at three angles $\left(0^{\circ}, 45^{\circ}\right.$ and $90^{\circ}$ ). This procedure was performed every day from the seedling stages until maturity. Image processing was performed using LemnaGrid software from LemnaTe ${ }^{57}$ in the following sequence: 1) nearest neighbour foreground/background colour separation was used to classify pixels. Two sets of colour intensities, corresponding to foreground (target) and to background (non target) were selected. RGB pixels matching selected intensities were mapped onto the image. A search around mapped pixels was performed to identify pixels with similar intensities that might be part of the foreground/background regions. Once the search was performed, the image was converted to binary form, where 1 is the target (plant) and 0 the background (compost, tray, etc.). 2) Morphological techniques were then applied to deal with pixels that were incorrectly classified. First, morphological erosion was applied to remove small and isolated pixel regions that were incorrectly classified as plant. Second, morphological dilation was applied to correct for pixels located in the border of the images that were incorrectly classified as background. 3) A final filter operation used a Region of Interest (ROI) to mark the approximate region occupied by a wheat plant at maturity. Once the images were segmented the green area was calculated.

Dry matter partitioning, grain yield and agronomic components. In Experiment 1 , wheat plants were harvested at maturity, separated into shoot and roots and dried in a fan-forced oven at $60^{\circ} \mathrm{C}$ for $48 \mathrm{~h}$. The spikes were counted and threshed manually. The grains were counted using a feed seed counter (ELE International, USA). The evaluated traits were: DW, GY, root:shoot ratio (R:S), harvest index (HI), number of spikes per plant (SP), number of kernels per spike (KS) and per plant (KP), and thousand kernel weight (TKW). DW and spike weight were also measured at harvest in Experiment 2.

Plant water-use efficiency. Apparent water use (WU) per genotype and water condition was estimated from the water-supplied data. Water supply during irrigation was fully retained by the substrate, therefore there was no water loss from the pots due to drainage. Evaporation from the pot surface was not prevented, it was assumed similar for all genotypes. Plant water use efficiency was calculated as DW/WU. There were four and five replicate pots per genotype and water condition in Experiment 1 and 2, respectively.

Carbon discrimination in kernels (Experiment 1). The carbon isotope ratio $\left({ }^{13} \mathrm{C} /{ }^{12} \mathrm{C}\right)$ was determined in mature kernels using an elemental analyser (ANCA-SL, PDZ Europa, UK) coupled with an isotope ratio mass spectrometer, at the Laboratory of Applied Physical Chemistry at Ghent University (Belgium). The ${ }^{13} \mathrm{C} /{ }^{12} \mathrm{C}$ ratios were expressed as carbon isotope composition: $\delta^{13} \mathrm{C}=\left(\left(\left({ }^{13} \mathrm{C} /{ }^{12} \mathrm{C}\right)_{\text {sample }} /\left({ }^{13} \mathrm{C} /{ }^{12} \mathrm{C}\right)_{\text {standard }}\right)-1\right)$, where sample refers to plant material and standard to the laboratory standards that have been calibrated against international standards from Iso-Analytical (Crewe, Cheshire, UK). The precision of $\delta^{13} \mathrm{C}$ analyses was $0.3 \%$. Further, the carbon isotope discrimination $\left(\Delta^{13} \mathrm{C}\right)$ of kernels was calculated as: $\Delta^{13} \mathrm{C}(\%)=\left(\delta^{13} \mathrm{Ca}-\delta^{13} \mathrm{Cp}\right) /\left[1+\left(\delta^{13} \mathrm{Cp}\right) / 1000\right]$, where a and $\mathrm{p}$ refer to air and the plant, respectively ${ }^{58}$.

Data analysis. Differences among genotypes $(\mathrm{G})$ and water condition (W) were determined through analysis of variance (ANOVA) using the general linear model (GLM) procedure of the SPSS statistical package. In addition, relationships between traits were performed using Pearson correlations, and linear and non-linear regression analysis. For the leaf gas exchange, chlorophyll fluorescence and chlorophyll index data, the ANOVAs were performed using $\mathrm{G}, \mathrm{W}$ and phenology $(\mathrm{P})$ as fixed factors. For the plant traits, the ANOVAs were performed using $\mathrm{G}$ and $\mathrm{W}$ as fixed factors.

Received: 7 February 2019; Accepted: 8 December 2019;

Published online: 16 January 2020

\section{References}

1. IPCC (Intergovernmental Panel on Climate Change). Climate Change 2007: Synthesis Report. A Report of the Intergovernmental Panel on Climate Change. Geneva, Switzerland (2007).

2. Kelley, C., Mohtadi, S., Cane, M. A., Seager, R. \& Kushnir, Y. Climate change in the Fertile Crescent and implications of the recent Syrian drought. PNAS 112, 3241-3246 (2015). 
3. Guiot, J. \& Cramer, W. Climate change: The 2015 Paris Agreement thresholds and Mediterranean basin ecosystems. Science 354, 465-468 (2016).

4. Garreaud, R. et al. The 2010-2015 mega drought in Central Chile: Impacts on regional hydroclimate and vegetation. Hydrol. Earth Syst. Sci. 21, 6307-6327, https://doi.org/10.5194/hess-2017-191 (2017).

5. Tambussi, E. A., Bort, J. \& Araus, J. L. Water use efficiency in C3 cereals under Mediterranean conditions: a review of physiological aspects. Ann. Appl. Biol. 150, 307-321 (2007).

6. Sikder, S. et al. Evaluation of photosynthetic potential of wheat genotypes under drought condition. Photosynthetica 53, 47-54 (2015)

7. Guan, X. -K., Song, L., Wang, T. -C., Turner, N. C. \& Li, F. -M. Effect of drought on the gas exchange, chlorophyll fluorescence and yield of six different-era spring wheat cultivars. J. Agron. Crop Sci. 201, 253-266 (2015).

8. Passioura, J. B. Increasing crop productivity when water is scarce-from breeding to field management. Agric. Water Manage. 80, 176-196 (2006).

9. Baker, N. R. Chlorophyll fluorescence: a probe of photosynthesis in vivo. Annu. Rev. Plant Biol. 59, 89-113 (2008).

10. Beer, S. \& Björk, M. Measuring rates of photosynthesis of two tropical seagrasses by pulse amplitude modulated (PAM) fluorometry. Aquat. Bot. 66, 69-76 (2000).

11. Schreiber, U. Pulse-Amplitude-Modulation (PAM) Fluorometry and Saturation Pulse Method: An Overview. Advances in Photosynthesis and Respiration book series (AIPH, volume 19), Chapter 11 (2004).

12. Ralph, P. J. \& Gademann, R. Rapid light curves: a powerful tool to assess photosynthetic activity. Aquat. Botany. 82, 222-237 (2005).

13. Klughammer, C. \& Schreiber, U. Complementary PS II quantum yields calculated from simple fluorescence parameters measured by PAM fluorometry and the Saturation Pulse method. P.A.N. E.-J. 1, 27-35 (2008).

14. Condon, A. G., Richards, R. A., Rebetzke, G. J. \& Farquhar, G. D. Breeding for high water-use efficiency. J. Exp. Bot. 55, 2447-2460 (2004).

15. Araus, J. L., Slafer, G. A., Reynolds, M. \& Royo, C. Plant breeding and drought in C3 cereals: What should we breed for? Ann. Bot. 89, 925-940 (2002).

16. Blum, A. Effective use of water (EUW) and not water use efficiency (WUE) is the target of crop yield improvement under drought stress. Field Crops Res. 112, 119-123 (2009).

17. Farquhar, G. D. \& Richards, R. A. Isotopic composition of plant carbon correlates with water-use efficiency of wheat genotypes. Aust. J. Plant Physiol. 11, 539-552 (1984).

18. Morrinson, J. I. L., Baker, N. R., Mullineaux, P. M. \& Davies, W. J. Improving water use in crop production. Phil. Trans. R. Soc. 363, 639-658 (2008)

19. Yasir, T. A., Min, D., Chen, X., Condon, A. G. \& Hu, Y.-G. The association of carbon isotope discrimination $(\Delta)$ with gas exchange parameters and yield traits in Chinese bread wheat cultivars under two water regimes. Agric. Water Manag. 119, 111-120 (2013).

20. del Pozo, A. et al. Physiological traits associated with wheat yield potential and performance under water-stress in a Mediterranean environment. Front. Plant Sci. https://doi.org/10.3389/fpls.2016.00987 (2016)

21. Jimenez, F. et al. Physiological, biochemical and molecular characterization of an induced mutation conferring imidazolinone resistance in wheat. Physiol. Plant. 158, 2-10 (2016).

22. del Pozo, A., Matus, I., Araus, J. L. \& Serret, D. Agronomic and physiological traits associated with breeding advances of wheat under high-productive Mediterranean conditions. The case of Chile. Environ. Exper. Bot. 103, 180-189 (2014).

23. Royo, C. et al. Genetic changes in durum wheat yield components and associated traits in Italian and Spanish varieties during the 20th century. Euphytica 155, 259-270 (2007).

24. Fischer, R. A. et al. Wheat yield progress associated with higher stomatal conductance and photosynthetic rate, and cooler canopies. Crop Sci. 38, 1467-1475 (1998).

25. Zheng, T. C. et al. Genetic gains in grain yield, net photosynthesis and stomatal conductance achieved in Henan Province of China between 1981 and 2008. Field Crops Res. 122, 225-233 (2011).

26. Carmo-Silva, E. et al. Phenotyping of field-grown wheat in the UK highlights contribution of light response of photosynthesis and flag leaf longevity to grain yield. J. Exp. Bot. 61, 235-261 (2017).

27. Rivero, R. M. et al. Delayed leaf senescence induces extreme drought tolerance in a flowering plant. PNAS 104, 19631-19636 (2007).

28. Lopes, M. S. \& Reynolds, M. P. Stay-green in spring wheat can be determined by spectral reflectance measurements (normalized difference vegetation index) independently from phenology. J. Exp. Bot. https://doi.org/10.1093/jxb/ers07 (2012).

29. Spano, G. et al. Physiological characterization of 'stay green' mutants in durum wheat. J. Exp. Bot. 54, 1415-1420 (2003).

30. Blake, N. K., Lanning, S. P., Martin, J. M., Sherman, J. D. \& Talbert, L. E. Relationship of flag leaf characteristics to economically important traits in two spring wheat crosses. Crop Sci. 47, 491-496 (2007).

31. Wang, H., Mccaig, T. N., Depauw, R. M. \& Clarke, J. M. Flag leaf physiological traits in two high-yielding Canada western red spring wheat cultivars. Can. J. Plant Sci. 88, 35-42 (2008).

32. Li, Q. et al. Differential effect of whole-ear shading after heading on the physiology, biochemistry and yield index of stay-green and non-stay-green wheat genotypes. PloS one 12(2), e0171589 (2017).

33. Wang, W. et al. Improved salt tolerance in a wheat stay-green mutant tasg1. Acta Physiologiae Plantarum 40(2), 39 (2018).

34. Araus, J. L., Amaro, T., Voltas, J., Nakkoul, H. \& Nachit, M. M. Chlorophyll fluorescence as a selection criterion for grain yield in durum wheat under Mediterranean conditions. Field Crops Res. 55, 209-223 (1998).

35. Dulai, S. et al. Effects of drought on photosynthetic parameters and heat stability of PSII in wheat and in Aegilops species originating from dry habitats. Acta Biol. Szeged. 50, 11-17 (2006).

36. Sharma, D. K., Andersen, S. B., Ottosen, C. O. \& Rosenqvist, E. Wheat cultivars selected for high Fv/Fm under heat stress maintain high photosynthesis, total chlorophyll, stomatal conductance, transpiration and dry matter. Physiol. Plant. 153, 284-298 (2015).

37. Sun, W. et al. Different mechanisms of photosynthetic response to drought stress in tomato and violet orychophragmus. Photosynthetica 54, 226-233 (2016)

38. Mouradi, M. et al. Effects of water deficit on growth, nodulation and physiological and biochemical processes in Medicago sativarhizobia symbiotic association. Arid Land Res. Manag. 30, 193-208 (2015).

39. Yi, X. et al. Rapid recovery of photosynthetic rate following soil water deficit and re-watering in cotton plants (Gossypium herbaceum L.) is related to the stability of the photosystems. J. Plant Physiol. 194, 23-34 (2016).

40. Lawlor, D. W. Limitation to photosynthesis in water-stressed leaves: Stomata vs. metabolism and the role of ATP. Ann. Bot. 89, 871-885 (2002).

41. Flexas, J. \& Medrano, H. Drought-inhibition of photosynthesis in C3 plants: stomatal and non-stomatal limitations revisited. Ann Bot. 89, 183-189 (2012).

42. Lawlor, D. W. \& Cornic, G. Photosynthetic carbon assimilation and associated metabolism in relation to water deficits in higher plants. Plant Cell Environ. 25, 275-294 (2002).

43. Flexas, J. et al. Understanding down-regulation of photosynthesis under water stress: future prospects and searching for physiological tools for irrigation management. Ann. Appl Biol. 144, 273-283 (2004).

44. Flexas, J., Carriquí, M. \& Nadal, M. Gas exchange and hydraulics during drought in crops: who drives whom? J. Exp. Bot. 69, 3791-3795 (2018).

45. Campos, H. et al. Stomatal and non-stomatal limitations of bell pepper (Capsicum annuum L.) plants under water stress and rewatering: Delayed restoration of photosynthesis during recovery. Environ. Exper. Bot. 98, 56-64 (2014). 
46. Zhou, S., Medlyn, B., Sabaté, S., Sperlich, D. \& Prentice, I. C. Short-term water stress impacts on stomatal, mesophyll and biochemical limitations to photosynthesis differ consistently among tree species from contrasting climates. Tree Physiol. 34, 1035-1046 (2014).

47. Chaves, M. M. et al. How plants cope with water stress in the field? Photosynthesis and growth. Ann. Bot. 89, 907-916 (2002).

48. Medrano, H. et al. From leaf to whole-plant water use efficiency (WUE) in complex canopies: Limitations of leaf WUE as a selection target. The Crop. Journal 3, 220-228 (2015).

49. Condon, A. G., Farquhar, G. D. \& Richards, R. A. Genotypic variation in carbon isotope discrimination and transpiration efficiency in wheat. Leaf gas exchange and whole plant studies. Aust. J. Plant Physiol. 17, 9-22 (1990).

50. Araus, J. L. et al. Environmental factors determining carbon isotope discrimination and yield in durum wheat under Mediterranean conditions. Crop Sci. 43, 170-180 (2003).

51. Araus, J. L., Cabrera-Bosquet, L., Serret, M. D., Bort, J. \& Nieto-Taladriz, M. T. Comparative performance of $\delta 13 \mathrm{C}, \delta 18 \mathrm{O}$ and $\delta 15 \mathrm{~N}$ for phenotyping durum wheat adaptation to a dryland environment. Funct. Plant Biol. 40, 595-608 (2013).

52. del Pozo, A. et al. Improving drought tolerance of barley using Hordeum vulgare subsp. spontaneum as a source of donor alleles in a Hordeum vulgare subsp. vulgare background. Ann. Appl. Biol. 160, 157-167 (2012).

53. Rebetzke, G. J., Condon, A. G., Farquhar, G. D., Appels, R. \& Richards, R. A. Quantitative trait loci for carbon isotope discrimination are repeatable across environments and wheat mapping populations. Theor. Appl. Genet. 118, 123-137 (2008).

54. Araus, J. L., Slafer, G. A., Royo, C. \& Serret, M. D. Breeding for yield potential and stress adaptation in cereals. Crit. Rev. Plant Sci. 27, 377-412 (2008).

55. Zadoks, J. C., Chang, T. T. \& Konzak, C. F. A decimal code for the growth stages of cereals. Weed Research 14, 415-421 (1974),

56. Eilers, P. H. C. \& Peeters, J. C. H. A model for the relationship between light intensity and the rate of photosynthesis in phytoplankton. Ecol. Model. 42, 199-215 (1988).

57. LemnaTec. LemnaLauncher Image analysis. LemnaLauncher and LemnaMiner Manual. Würselen, Germany: Lemnatec. Ipp. $112-186$ (2010).

58. Farquhar, G. D., Ehleringer, J. R. \& Hubick, K. T. Carbon isotope discrimination and photosynthesis. Annu. Rev. Plant Phys. 40, 503-537 (1989).

\section{Acknowledgements}

This work was supported by the research grants FONDECYT N ${ }^{\circ} 1150353$ and 1180252, and PIEI "Adaptación de la Agricultura al Cambio Climático (A2C2)", Universidad de Talca and by BBSRC grants BB/J004464/1, BB/ M018407/1 and BB/CAP1730/1. We also appreciate and acknowledge the assistance of the NPPC staff.

\section{Author contributions}

A.M.M., S.R., M.G., F.E. and M.A. managed the glasshouse experiment and performed the evaluations at Universidad de Talca. F.C., J.D., S.R. and A.C.R. conducted the experiment at NPPC. A.D.P., A.M., G.L., A.C.R. and S.R. performed the data analysis. A.D.P. was in charge of the writing but all the authors contributed to the manuscript.

\section{Competing interests}

The authors declare no competing interests.

\section{Additional information}

Supplementary information is available for this paper at https://doi.org/10.1038/s41598-019-57116-0.

Correspondence and requests for materials should be addressed to A.d.P.

Reprints and permissions information is available at www.nature.com/reprints.

Publisher's note Springer Nature remains neutral with regard to jurisdictional claims in published maps and institutional affiliations.

(c) (1) Open Access This article is licensed under a Creative Commons Attribution 4.0 International License, which permits use, sharing, adaptation, distribution and reproduction in any medium or format, as long as you give appropriate credit to the original author(s) and the source, provide a link to the Creative Commons license, and indicate if changes were made. The images or other third party material in this article are included in the article's Creative Commons license, unless indicated otherwise in a credit line to the material. If material is not included in the article's Creative Commons license and your intended use is not permitted by statutory regulation or exceeds the permitted use, you will need to obtain permission directly from the copyright holder. To view a copy of this license, visit http://creativecommons.org/licenses/by/4.0/.

(C) The Author(s) 2020 